\title{
Minor Physical Anomalies Among Schizophrenic Patients as a Biomarker of Its Developmental Origin in Northwest Ethiopia
}

This article was published in the following Dove Press journal: Neuropsychiatric Disease and Treatment

\section{Binalfew Tsehay (D) \\ Desalegn Shitie}

Department of Biomedical Sciences, Debre Markos University, Debre Markos, Ethiopia
Correspondence: Binalfew Tsehay Department of Biomedical Sciences, Debre Markos University, P. O. Box 269, Debre Markos, Ethiopia

Tel +25I 910287723

Email bunadmu@gmail.com
Purpose: Although there are highly precise and advanced diagnostic methods, the etiology and pathophysiology of schizophrenia remain poorly understood. There are several theories about schizophrenia origin, among which the neurodevelopmental theory is widely accepted. Our study aimed to assess minor physical anomalies among schizophrenic patients as putative indices of its developmental origin in North West Ethiopia 2018-2019.

Patients and Methods: Institutional-based comparative cross-sectional study design was conducted in Debre Markos comprehensive, specialized hospitals in 190 schizophrenic patients, 190 healthy controls, and 190 1st-degree relatives. Data were collected using standard methods, entered into EpiData version 3.1, and exported to SPSS version 24 for analysis. Descriptive data were analyzed using descriptive statistics, and discriminant function analysis was conducted and a value of 0.03 was taken as the cutoff point for prediction of group status of the study samples. Results: Five hundred seventy study samples, male 375 (65.8\%), and female 195 (34.2\%), were included in this study. The discriminate function 1 and 2 revealed a significant association between groups and all predictors, accounting for $83.5 \%$ and $16.5 \%$ of between-group variability, respectively. However, closer analysis of the structure matrix revealed longitudinally furrowed tongue, $\geq$ Five palate ridges, high steeples palate, transversely and randomly furrowed tongue, protruding supraorbital ridge as significant predictors.

Conclusion: Depending on predictor variables in this study, minor physical anomalies can serve as a biomarker for early screening of schizophrenic patients and clue for its developmental origin.

Keywords: minor physical anomalies, schizophrenia, neurodevelopment, Ethiopia

\section{Introduction}

Although there are highly precise and advanced diagnostic methods, the etiology and pathophysiology of schizophrenia remain poorly understood. There are several theories about schizophrenia origin, among which the neurodevelopmental theory is widely accepted. $^{1-3}$

According to the neurodevelopmental approach to schizophrenia developmental insults, both genetic and environmental, during early life underlies the structural and functional changes in the brain and the face. These neurodevelopmental disorders are often concentrated in the craniofacial region of schizophrenics but are clinically dormant until after puberty.,

Though the period of insult was difficult to assess directly, there are various sets of evidence that emphasize early life exposure to schizophrenia. One approach to 
studying neurodevelopmental disturbances among schizophrenic patients is somatic physical evidence or neurodevelopmental markers. These markers are measurable in adults and reflect abnormal neurodevelopmental processes that occurred before or shortly after birth. ${ }^{6,7}$ Minor physical anomalies and dermatoglyphic features are somatic physical markers of prenatal disruptions.

Minor physical anomalies (MPAs), are subtle abnormal features of the head, eyes, ears, mouth, hands, and feet. ${ }^{8,9}$ MPAs are of no serious medical significance, but they indicate the possible presence of associated major anomalies. ${ }^{10,11}$ As the brain and skin are derived from the neuroectodermal layer of an embryo, the presence of multiple MPAs could suggest the possibility of an underlying genetic and/or environmental insult affecting organogenesis. ${ }^{12}$ Furthermore, since the way and the timing of the disturbance(s) during early life is not clear, the distribution of MPAs could provide clues to the pathophysiology of schizophrenia as they reflect adverse events during critical periods of development, ${ }^{13}$ usually within the first or early second trimester. ${ }^{11}$

So, an early assessment of the minor physical anomalies may indicate potential clues of neurodevelopmental disorders like schizophrenia. ${ }^{14-16}$ Numerous studies report an increased frequency of minor physical anomalies (MPAs) in schizophrenic individuals compared with controls. A meta-analysis was carried out on the existing MPA literature to better understand the relationship between MPAs and schizophrenia. The regional MPA analysis revealed significantly increased MPAs in all six anatomical regions. ${ }^{17}$ The findings of other meta-analysis indicated that MPAs have been demonstrated in patients with schizophrenia as compared to healthy controls, and a lesser extent in unaffected relatives. These findings supported the idea that MPAs may represent a putative endophenotype for schizophrenia. However, it recommended more research including first-degree family members is warranted. ${ }^{18}$ Minor physical anomalies can be measured using the Waldrop Scale. ${ }^{8}$ This research assessed the potential value of exploring minor physical anomalies among schizophrenic patients for early screening of disease among patients and controls objectively and as part of studying its etiology in the northwest, Ethiopia.

\section{Patients and Methods}

\section{Study Design and Setting}

The institutional-based comparative cross-sectional study design was conducted. This study was undertaken from October 2018 to September 2019 in the psychiatry unit of Debre Markos Referral Hospital. Debre Markos has located $300 \mathrm{~km}$ from Addis Ababa, the capital of Ethiopia, and $256 \mathrm{~km}$ from Bahir-Dar, the capital of Amhara Regional State. Debre Markos Referral Hospital is the only referral hospital found in East Gojjam Zone and serves $>3.5$ million people in its catchment area.

\section{Population}

The Study populations were all schizophrenic patients, $1^{\text {st }}$ degree relatives, and healthy controls in the psychiatry outpatient department who fulfill the definition criteria for this particular study. Schizophrenic patients were those schizophrenic patients diagnosed using the DSM-III-R whereas controls were those patients without mental disorders.

\section{Eligibility Criteria}

Inclusion Criteria

All samples who met the case $/ 1^{\text {st }}$ degree relative/control definition; and who volunteered to participate.

\section{Exclusion Criteria}

Any history of head injury, epilepsy, significant alcohol or drug abuse, oral-maxillofacial surgery, and those seriously ill patients

\section{Sample Size and Sampling Procedure}

The sample size was calculated using Fleiss with CC Formula on epi info version 7.0 software; by setting a significance level of $95 \%$, power of $80 \%$, and a casecontrol ratio of $1: 1$. The final sample size was 570 , (190 schizophrenic patients, $1901^{\text {st }}$ degree relatives), and 190 Controls. A purposive sampling technique was used to select the study samples.

\section{Variables of the Study Independent Variables}

Socio-demographic characteristics and minor physical anomalies

\section{Dependent Variable}

Patient control status of schizophrenia

\section{Operational Definitions} Schizophrenia

Schizophrenia is a severe mental disorder, diagnosed subjectively using DSM-III-R, patient.

Minor Physical Anomalies

Are cosmetically insignificant subtle defects of the craniofacial region, hands, and feet which are not detrimental to health. 


\section{First Degree Relatives (FDR)}

Mother or father or sister or brother or children of the case.

\section{Data Collection Procedure}

Socio-demographic and psychiatric characteristics of the study sample were collected using a structured interviewer-administered questionnaire. Diagnose of the patient was conducted based on the structured clinical interview for DSM-III-R, patient version (SCID-P, version 1.0). The presence and absence of MPAs were assessed in 6 regions (head, eye, ear, mouth, hand, and feet) using a modified Waldrop scale, ${ }^{8}$ incorporating 25 elements.

\section{Data Quality Assurance}

Data were collected by trained data collectors with strict supervision. Data collection tools were pretested. Two days of training were given for data collectors about the objectives of the study, the contents of the Waldrop scale and questionnaire, data collection techniques, and ethical issues. The principal investigator and supervisors supervised the overall data collection procedure on daily basis. Data were collected by two trained midwives.

\section{Data Analysis}

Data were entered via Epi data version 3.1 and analyzed using SPSS version 24. Chi-square tests were used to select variables to be entered into a multivariate discriminant analysis. Independent variables that had a significant relationship with schizophrenia at a $p<0.05$ level were retained for inclusion in the analysis. Discriminant Function Analysis undertakes the same task as multiple linear regression by predicting an outcome. Discriminant function analysis assumes that the sample is normally distributed for the trait. Just like factor loadings, 0.30 was seen as the cut-off between important and less important predictor variables.

\section{Results}

\section{Socio-Demographic Characteristics of the Study Samples}

A total of 570 study samples, male 375 (65.8\%), and female $195(34.2 \%)$ were included in this study. The mean ages of schizophrenics, their 1st-degree relatives, and healthy controls were 35.62 years, 39.97 years, and 33.56 years respectively with no significant difference between patients and control. All study populations were aged between 16 to 74 years with a mean age of 36.38 years and $318(55.8 \%)$ were married. Most of the study population were from Amhara with an annual income of 25,000-50,000 (Table 1). 93.2\% of schizophrenic patients experienced early-onset schizophrenia.

\section{Minor Physical Anomalies (MPAs)}

The presence and absence of MPAs were assessed qualitatively in 6 regions (head, eye, ear, mouth, hand, and feet) using a modified Waldrop scale, incorporating 25 elements. For continuous variables, (head circumference and intercanthal distance), we had categorized as normal and

Table I Socio-Demographic Characteristics of Schizophrenic Patients, Their First-Degree Relatives and Healthy Control $(\mathrm{N}=570)$

\begin{tabular}{|c|c|c|c|}
\hline Variables & Category & Number & Percent \\
\hline \multirow[t]{2}{*}{ Sex } & Male & 375 & 65.8 \\
\hline & Female & 195 & 34.2 \\
\hline \multirow[t]{2}{*}{ Age } & $<18$ & 2 & 0.4 \\
\hline & $\geq 18$ & 568 & 99.6 \\
\hline \multirow{2}{*}{$\begin{array}{l}\text { Religious responsibility } \\
\text { of the sample }\end{array}$} & Yes & 26 & 4.6 \\
\hline & No & 544 & 95.4 \\
\hline \multirow{4}{*}{$\begin{array}{l}\text { marital status of the } \\
\text { study sample }\end{array}$} & Married & 318 & 55.8 \\
\hline & Unmarried & 179 & 31.4 \\
\hline & Divorced & 64 & 11.2 \\
\hline & Widowed & 9 & 1.6 \\
\hline \multirow[t]{5}{*}{ Educational status } & Below 8th & 293 & 51.4 \\
\hline & $9-12$ & 89 & 15.6 \\
\hline & Diploma & 161 & 28.2 \\
\hline & Degree & 21 & 3.7 \\
\hline & Master and $\mathrm{PhD}$ & 6 & I.I \\
\hline \multirow[t]{5}{*}{ Ethnicity } & Amhara & 553 & 97.0 \\
\hline & Oromo & 3 & 0.5 \\
\hline & Tigrie & 8 & 1.4 \\
\hline & SNNPE* & 3 & 0.5 \\
\hline & Others* & 3 & 0.5 \\
\hline \multirow[t]{4}{*}{ Occupation } & Farmers & 228 & 40.0 \\
\hline & private employee & 140 & 24.6 \\
\hline & $\begin{array}{l}\text { government } \\
\text { employee }\end{array}$ & 165 & 28.9 \\
\hline & Merchant & 37 & 6.5 \\
\hline \multirow{6}{*}{$\begin{array}{l}\text { Annual income of the } \\
\text { study sample/family } \\
\text { (birr) }\end{array}$} & $>250,000$ & 2 & 0.4 \\
\hline & $100,000-250,000$ & 9 & 1.6 \\
\hline & $75,000-100,000$ & 24 & 4.2 \\
\hline & $50,000-75,000$ & 72 & 12.6 \\
\hline & $25,000-50,000$ & 312 & 54.7 \\
\hline & $<25,000$ & $|5|$ & 26.5 \\
\hline
\end{tabular}

Notes: *SNNP- southern nations nationalities and peoples of Ethiopia. *OthersAgaw, Benishangul-Gumuz 
abnormal depending on the mean of the control group. If the mean value of patient and first-degree relatives lies within two standard deviations of the control, it was labeled as normal. If the mean value lies outside the two standard deviations of the control mean considered abnormal' ie subnormal or supernormal. The inter-rater reliability, evaluated using the intra-class correlation coefficient was 0.97 .

After adjusting the above-mentioned procedures chisquare test was conducted. A higher frequency of some minor physical anomalies was observed in schizophrenic patients than healthy control and their $1^{\text {st }}$-degree relatives. The highest difference was found for the high steepled palate, $\geq$ Five palate ridges, longitudinally furrowed, transversely, and randomly furrowed tongue which appeared in schizophrenic patients with high frequency $(\mathrm{p}<0.001)$ (Table 2).

\section{Discriminant Function Analysis}

The multivariate discriminant analysis was performed in the field of minor physical anomalies. Two discriminant functions were obtained by multivariate discriminant analysis of variables with p-value $<0.05$ in the chi-square test. These functions statistically significantly differentiated the groups of subjects included in the analysis. While the $\log$ determinants were quite similar, Box's $M$ indicated that the assumption of the equality of covariance matrices was violated. However, given the large sample, this problem is not regarded as serious. The discriminate function 1 and 2 revealed a significant association between groups and all predictors, accounting for $83.5 \%$ and $16.5 \%$ of betweengroup variability respectively (Table 3 ).

This structure matrix table shows the correlations of each variable with each discriminate function. These Pearson coefficients are structure coefficients or discriminant loadings. They serve like factor loadings in factor analysis. Longitudinally furrowed tongue, $\geq$ Five palate ridges, high steepled palate, abnormal intercanthal distance, abnormal head circumference, the anticlockwise direction of hair whorls, coverage of epicanthus, the curvature of the fifth finger, slanted eye fissure, displayed the highest correlations with the first discriminant function. Generally, just like factor loadings, 0.30 is seen as the cut-off between important and less important variables. Based on this, longitudinally furrowed tongue $(\mathrm{r}=0.587), \geq$ Five palate ridges $(\mathrm{r}=0.354)$, high steepled palate $(\mathrm{r}=0.331)$ strongly predict allocation to the schizophrenic patients, their $1^{\text {st }}$-degree relatives, and healthy

Table 2 Topographical Distribution and Frequencies of Minor Physical Anomalies Between Schizophrenic Patients, I ${ }^{\text {st }}$-Degree Relatives, and Healthy Controls

\begin{tabular}{|c|c|c|c|c|c|}
\hline & Minor Anomaly & $\begin{array}{l}\text { Schizophrenic } \\
\text { Patients } \\
(\mathrm{N}=190) \mathrm{N}(\%)\end{array}$ & $\begin{array}{l}\text { Ist Degree } \\
\text { Relatives } \\
(\mathrm{N}=\mid 90) \mathbf{N}(\%)\end{array}$ & $\begin{array}{l}\text { Healthy } \\
\text { Control } \\
(\mathrm{N}=190) \mathrm{N}(\%)\end{array}$ & $\begin{array}{l}\text { Chi-Square } \\
(\chi 2 \text { Test) }\end{array}$ \\
\hline Head & $\begin{array}{l}\text { Anticlockwise hair whorl direction } \\
\geq \text { Two number of hair whorls } \\
\text { Abnormal head circumference }\end{array}$ & $\begin{array}{l}39(20.5 \%) \\
16(8.4 \%) \\
40(21.1 \%)\end{array}$ & $\begin{array}{l}58(30.5 \%) \\
\mathrm{II}(5.8 \%) \\
18(9.5 \%)\end{array}$ & $\begin{array}{l}64(33.7 \%) \\
12(6.3 \%) \\
25(13.2 \%)\end{array}$ & $\begin{array}{l}\chi 2=8.847 p=0.012 * \\
\chi 2=1.156 p=0.561 \\
\chi 2=10.689 p=0.005 *\end{array}$ \\
\hline Eyes & $\begin{array}{l}\text { Protruding supraorbital ridge } \\
\text { Coverage of Epicanthus } \\
\text { Slanted eye fissure } \\
\text { Abnormal intercanthal distance }\end{array}$ & $\begin{array}{l}33(17.4 \%) \\
18(9.5 \%) \\
43(22.6 \%) \\
34(17.9 \%)\end{array}$ & $\begin{array}{l}31(16.3 \%) \\
7(3.7 \%) \\
29(15.3 \%) \\
17(8.9 \%)\end{array}$ & $\begin{array}{l}17(8.9 \%) \\
7(3.7 \%) \\
25(13.2 \%) \\
12(6.3 \%)\end{array}$ & $\begin{array}{l}\chi 2=6.562 \mathbf{p}=0.038^{*} \\
\chi 2=8.012 \mathrm{p}=0.018^{*} \\
\chi 2=6.659 \mathrm{p}=0.036^{*} \\
\chi 2=\mid 4.241 \mathrm{p}=0.001 * *\end{array}$ \\
\hline Ear & $\begin{array}{l}\text { Low seated ears } \\
\text { Adherence of ear lobes } \\
\text { Hypoplastic }\end{array}$ & $\begin{array}{l}23(\mid 2.1 \%) \\
131(68.9 \%) \\
19(41.3 \%)\end{array}$ & $\begin{array}{l}7(3.7 \%) \\
116(61.1 \%) \\
14(30.4 \%)\end{array}$ & $\begin{array}{l}15(7.9 \%) \\
103(54.2 \%) \\
13(28.3 \%)\end{array}$ & $\begin{array}{l}\chi 2=9.265 \mathrm{p}=0.010 * \\
\chi 2=8.720 \mathrm{p}=0.013^{*} \\
\chi 2=1.466 \mathrm{p}=0.480\end{array}$ \\
\hline Mouth & $\begin{array}{l}\text { High steepled palate } \\
\geq \text { Five palate ridges } \\
\text { Longitudinally furrowed } \\
\text { Transversely and randomly furrowed } \\
\text { tongue }\end{array}$ & $\begin{array}{l}34(17.9 \%) \\
48(25.3 \%) \\
77(40.5 \%) \\
132(69.5 \%)\end{array}$ & $\begin{array}{l}9(4.7 \%) \\
19(10.0 \%) \\
22(11.6 \%) \\
134(70.5 \%)\end{array}$ & $\begin{array}{l}17(8.9 \%) \\
23(12.1 \%) \\
32(16.8 \%) \\
98(51.6 \%)\end{array}$ & $\begin{array}{l}\chi 2=18.218 \mathbf{p}<0.001 * * \\
\chi 2=19.554 \mathbf{p}<0.001 \\
\chi 2=51.044 \mathbf{p}<0.000 * * \\
\chi 2=18.670 \mathbf{p}<0.000 * *\end{array}$ \\
\hline Hound & Inward curvature of fifth finger & $60(31.6 \%)$ & $42(22.1 \%)$ & $39(20.5 \%)$ & $\chi 2=7.294 p=0.026 *$ \\
\hline
\end{tabular}

Notes: ** The highest significant differences between groups. *Shows significant differences between groups. 
Table 3 Canonical Discriminative Functions for the Group of Schizophrenic Patients, I ${ }^{\text {st }}$-Degree Relatives, and Healthy Control

\begin{tabular}{|c|c|c|c|c|c|c|c|c|c|}
\hline $\begin{array}{l}\text { Discriminant } \\
\text { Functions }\end{array}$ & Eigenvalue & $\begin{array}{l}\% \text { of } \\
\text { Variance }\end{array}$ & $\begin{array}{l}\text { Cumulative } \\
\%\end{array}$ & $\begin{array}{l}\text { Canonical } \\
\text { Correlation }\end{array}$ & $\begin{array}{l}\text { After } \\
\text { Discriminant } \\
\text { Function }\end{array}$ & $\begin{array}{l}\text { Wilks' } \\
\text { Lambda }\end{array}$ & $\begin{array}{l}\text { Chi- } \\
\text { Square }\end{array}$ & df & Sig. \\
\hline I. & 0.283 & 83.5 & 83.5 & 0.469 & 1 through 2 & 0.738 & 169.989 & 28 & 0.000 \\
\hline 2. & 0.056 & 16.5 & 100.0 & 0.230 & 2 & 0.947 & 30.507 & 13 & 0.004 \\
\hline
\end{tabular}

controls. Abnormal intercanthal distance $(\mathrm{r}=0.290)$ marginally predicts group status (Table 4).

The second discriminant function was mainly defined by four minor physical anomalies (Transversely and randomly furrowed tongue, protruding supraorbital ridge, adherence of ear lobes, low seated ears). From this transversely and randomly furrowed tongue $(\mathrm{r}=0.713)$, and protruding supraorbital ridge $(\mathrm{r}=0.382)$ had the highest correlations with this function and strongly predict group status (Table 4).

Generally, the regional minor physical anomalies (MPAs) scores that distinguished between schizophrenia patients and controls belonged mainly to the craniofacial region. All five significant minor physical anomalies included in the discriminant model were localized in the head and face.

\section{Discussion}

This study revealed that patients with schizophrenia showed five multiple minor physical anomalies in the

Table 4 Function-Variable Correlations for the Group of Schizophrenic Patients, I ${ }^{\text {st }}$-Degree Relatives, and Healthy Controls

\begin{tabular}{|l|l|l|}
\hline \multirow{2}{*}{ Variables } & \multicolumn{2}{l|}{ Function } \\
\cline { 2 - 3 } & $\mathbf{I}$ & $\mathbf{2}$ \\
\hline Longitudinally furrowed tongue & $\mathbf{0 . 5 8 7 ^ { * * }}$ & 0.146 \\
ZFive palate ridges & $\mathbf{0 . 3 5 4 ^ { * * }}$ & 0.053 \\
High steepled palate & $\mathbf{0 . 3 3} \mathbf{I}^{* *}$ & 0.196 \\
Abnormal intercanthal distance & $0.290^{*}$ & -.187 \\
Abnormal head circumference & $0.252^{*}$ & 0.148 \\
The anticlockwise direction of hair whorls & $-.227^{*}$ & 0.153 \\
Coverage of epicanthus & $-.225^{*}$ & 0.031 \\
The curvature of the fifth finger & $-.21 \mathbf{I}^{*}$ & 0.093 \\
Slanted eye fissure & $-.197^{*}$ & 0.125 \\
Transversely and randomly furrowed tongue & -.139 & $\mathbf{0 . 7 1 3 * *}$ \\
Protruding supraorbital ridge & -.111 & $\mathbf{0 . 3 8 2 * *}$ \\
Adherence of ear lobes & -.201 & $0.273^{*}$ \\
Low seated ears & -.217 & $-.243^{*}$ \\
\hline
\end{tabular}

Notes: *Largest absolute correlation between each variable and any discriminant function. $* *$ Strong predictors of group status craniofacial region, that readily distinguish them from control subjects.

Closer analysis of the structure matrix in our study revealed that longitudinally furrowed tongue, presence of $\geq$ Five palate ridges, high steepled palate; transversely and randomly furrowed tongue, and protruding supraorbital ridge were significant predictors of schizophrenic.

Generally, the regional minor physical anomalies (MPAs) scores that distinguished between schizophrenia patients and controls belonged mainly to the craniofacial region. All five significant minor physical anomalies included in the discriminant model were localized in the head and face.

This showed that MPAs associated with schizophrenia are commonly found in the craniofacial region. This is in line with previous studies on the topography of MPAs in schizophrenia, ${ }^{14,19-21}$ and is in support of the relation between early brain and craniofacial development. Minor physical anomalies in the craniofacial area can occur along with structural changes of the cerebrum in the intrauterine life of schizophrenics. ${ }^{8,22}$ These findings are consistent with a model of cerebro-craniofacial dysmorphogenesis. ${ }^{2}$

Many studies showed that the mouth region is highly susceptible to MPAs in schizophrenic patients, ${ }^{14,21,23}$ with the highest prevalence of the palate and tongue anomalies ${ }^{23-26}$ which is consistent with our study. Facial-cerebral morphogenesis postulated as dysmorphology in schizophrenia patients' face affects principally the midfacial region. ${ }^{27}$ During embryogenesis the midfacial region is populated with cranial neural crest cells, which could explain the coincidence of midfacial minor anomalies and schizophrenic disorder.

High/steepled palate represents a microform of cleft palate, which is itself frequently associated with midline brain anomalies as in fetal alcohol syndrome. Further, midline brain anomalies such as enlarged cavum septum pellucidum and corpus callosum abnormalities have been found with increased incidence in patients with schizophrenia. ${ }^{28,29}$

In this study longitudinal fissure of tongue and presence of tongue, furrow was found as significant predictors of schizophrenia. Most studies showed a furrowed tongue to 
be a significant marker of schizophrenia without respect to the type of furrows. ${ }^{30}$ While other studies reported randomly furrowed tongue, transversely furrowed tongue ${ }^{31}$ or longitudinal fissure of the tongue and few fissures diffusely distributed across the dorsal tongue surface. ${ }^{30}$

\section{Conclusion}

In our study closer analysis of the structure matrix revealed longitudinally furrowed tongue, $\geq$ Five palate ridges, high steepled palate; transversely and randomly furrowed tongue, protruding supraorbital ridge as a significant predictor. Depending on this study, minor physical anomalies can serve as a biomarker for early screening of schizophrenic patients and clue for its developmental origin as part of studying its etiology.

\section{Abbreviations}

DSM-III-R, Diagnostic and Statistical Manual of Mental Disorders; MPAs, minor physical anomalies; SCID-P, Structured Clinical Interview for DSM-III-R patient; ICD, intercanthal distance.

\section{Ethics Approval and Consent to Participate}

Written informed consent was obtained from the participants, and the study was conducted per the Declaration of Helsinki. The ethical clearance was taken from Debre Markos University, school of medicine Ethical review committee. The letter was formally submitted for Debre Markos' referral hospital and got permission.

\section{Acknowledgments}

We would like to say thank you to the Debre Markos university research directorate that sponsored us while collecting data. Debre Markos comprehensive specialized hospital staffs especially the psychiatric department thank you very much for your continuous support of the data collection procedure.

\section{Author Contributions}

Both authors contributed to data analysis, drafting or revising the article, have agreed on the journal to which the article was submitted, gave final approval of the version to be published, and agree to be accountable for all aspects of the work.

\section{Disclosure}

The authors declared that they have no competing interests in this work.

\section{References}

1. Compton MT, Walker EF. Physical manifestations of neurodevelopmental disruption: are minor physical anomalies part of the syndrome of schizophrenia? Schizophr Bull. 2009;35(2):425-436. doi:10.1093/ schbul/sbn 151

2. Waddington JL, Lane A, Scully P, et al. Early cerebro-craniofacial dysmorphogenesis in schizophrenia: a lifetime trajectory model from neurodevelopmental basis to 'neuroprogressive'process. J Psychiatr Res. 1999;33(6):477-489.

3. Akbarian S, et al. Altered distribution of nicotinamide-adenine dinucleotide phosphate-diaphorase cells in frontal lobe of schizophrenics implies disturbances of cortical development. Arch Gen Psychiatry. 1993;50(3):169-177. doi:10.1001/archpsyc.1993.018 20150007001

4. Waddington JL, Lane A, Larkin C, et al. The neurodevelopmental basis of schizophrenia: clinical clues from cerebro-craniofacial dysmorphogenesis, and the roots of a lifetime trajectory of disease. Biol Psychiatry. 1999;46(1):31-39. doi:10.1016/S0006-3223(99)00055-4

5. McGrath JJ, Féron FP, Burne TH, et al. The neurodevelopmental hypothesis of schizophrenia: a review of recent developments. Ann Med. 2003;35(2):86-93. doi:10.1080/07853890310010005

6. Green MF, Bracha HS, Satz P, et al. Preliminary evidence for an association between minor physical anomalies and second trimester neurodevelopment in schizophrenia. Psychiatry Res. 1994;53(2):119127. doi:10.1016/0165-1781(94)90103-1

7. McDonald C, Murray RM. Early and late environmental risk factors for schizophrenia. Brain Res Rev. 2000;31(2-3):130-137. doi:10.1016/S0165-0173(99)00030-2

8. Waldrop MF, Pedersen FA, Bell RQ. Minor physical anomalies and behavior in preschool children. Child Dev. 1968;39(2):391-400. doi:10.2307/1126953

9. Miles JH, Hillman RE. Value of a clinical morphology examination in autism. Am J Med Genet. 2000;91(4):245-253.

10. Sadler TW. Langman's Medical Embryology. Lippincott Williams \& Wilkins; 2011.

11. Moore KL, Persaud TVN, Torchia MG. The Developing Human-EBook: Clinically Oriented Embryology. Elsevier Health Sciences; 2018.

12. Jones KL, Jones MC, Del Campo M. Smith's Recognizable Patterns of Human Malformation E-Book. Elsevier Health Sciences; 2013.

13. Persaud T. Teralogenesis-experimental aspects and clinical implications. Exp Pathol (Jena). 1979;1-128.

14. Lane A, Kinsella A, Murphy P, et al. The anthropometric assessment of dysmorphic features in schizophrenia as an index of its developmental origins. Psychol Med. 1997;27(5):1155-1164. doi:10.1017/ S0033291797005503

15. McGrath J, Saha S, Welham J, et al. A systematic review of the incidence of schizophrenia: the distribution of rates and the influence of sex, urbanicity, migrant status and methodology. BMC Med. 2004;2(1):13. doi:10.1186/1741-7015-2-13

16. Elizarraas-Rivas J, Cerdan-Sanchez F-FR, Ramos-Zepeda LF, et al. Minor physical anomalies and anthropometric measures in schizophrenia: a pilot study from Mexico [Letter to the editor]. Schizoph Res. 2002;62.

17. Weinberg SM, Jenkins EA, Marazita ML, et al. Minor physical anomalies in schizophrenia: a meta-analysis. Schizophr Res. 2007;89(1-3):72-85. doi:10.1016/j.schres.2006.09.002

18. Xu T, Chan RCK, Compton MT, Hashimoto K. Minor physical anomalies in patients with schizophrenia, unaffected first-degree relatives, and healthy controls: a meta-analysis. PLoS One. 2011;6 (9):e24129. doi:10.1371/journal.pone.0024129 
19. Akabaliev VH, Sivkov ST, Mantarkov MY. Minor physical anomalies in schizophrenia and bipolar I disorder and the neurodevelopmental continuum of psychosis. Bipolar Disord. 2014;16(6):633-641. doi:10.1111/bdi.12211

20. Ismail B, Cantor-Graae E, McNeil TF. Minor physical anomalies in schizophrenic patients and their siblings. Am J Psychiatry. 1998;155 (12):1695-1702. doi:10.1176/ajp.155.12.1695

21. Sivkov ST, Akabaliev VH. Minor physical anomalies in schizophrenic patients and normal controls. Psychiatry. 2003;66(3):222-233. doi:10.1521/psyc.66.3.222.25163

22. O'Callaghan E, Buckley P, Madigan C, et al. The relationship of minor physical anomalies and other putative indices of developmental disturbance in schizophrenia to abnormalities of cerebral structure on magnetic resonance imaging. Biol Psychiatry. 1995;38(8):516524. doi:10.1016/0006-3223(94)00381-C

23. Green MF, Satz P, Gaier DJ, et al. Minor physical anomalies in schizophrenia. Schizophr Bull. 1989;15(1):91-99. doi:10.1093/schbul/15.1.91

24. DeLisi LE, et al. A family study of the association of increased ventricular size with schizophrenia. Arch Gen Psychiatry. 1986;43 (2):148-153. doi:10.1001/archpsyc.1986.01800020058007

25. Aksoy-Poyraz C, Poyraz BÇ, Turan Ş, et al. Minor physical anomalies and neurological soft signs in patients with schizophrenia and their siblings. Psychiatry Res. 2011;190(1):85-90. doi:10.1016/j. psychres.2011.04.023
26. Muramatsu D, Satz P, Gaier DJ, Ganzell S, Kharabi F. Minor physical anomaly in schizophrenia. Seishin Igaku. 2000.

27. Waddington JL, Lane LA, Scully P, et al. Early cerebro-craniofacial dysmorphogenesis in schizophrenia: a lifetime trajectory model from neurodevelopmental basis to 'neuroprogressive' process. J Psychiatr Res. 1999;33(6):477-489.

28. DeLisi LE, Hoff AL, Kushner M, et al. Increased prevalence of cavum septum pellucidum in schizophrenia. Psychiatry Res. 1993;50(3):193-199. doi:10.1016/0925-4927(93)90030-L

29. Swayze VW, Andreasen NC, Ehrhardt JC, et al. Developmental abnormalities of the corpus callosum in schizophrenia. Arch Neurol. 1990;47(7):805-808. doi:10.1001/archneur.1990.00530070103018

30. Babovic SS, Srdic-Galic B, Zigic S, et al. Craniofacial measures and minor physical anomalies in patients with schizophrenia in a cohort of Serbian population. Srp Arh Celok Lek. 2019;147(5-6):348-354. doi:10.2298/SARH180716056B

31. Akabaliev V, Sivkov S. Minor physical anomalies in schizophrenia. Folia Med (Plovdiv). 1998;40(2):39-45.
Neuropsychiatric Disease and Treatment

\section{Publish your work in this journal}

Neuropsychiatric Disease and Treatment is an international, peerreviewed journal of clinical therapeutics and pharmacology focusing on concise rapid reporting of clinical or pre-clinical studies on a range of neuropsychiatric and neurological disorders. This journal is indexed on PubMed Central, the 'PsycINFO' database and CAS, and is the official journal of The International Neuropsychiatric Association (INA). The manuscript management system is completely online and includes a very quick and fair peer-review system, which is all easy to use. Visit http://www.dovepress.com/testimonials.php to read real quotes from published authors. 